\title{
Cost Effective, High Efficiency INTEGRATED SYSTEMS APPROACH TO AUXILIARY ELECTRIC MOTORS
}

July 2003

PREPARED BY

Roy Kessinger (Pricipal Investigator)

Kanchan Angal

Steve W. Brewer

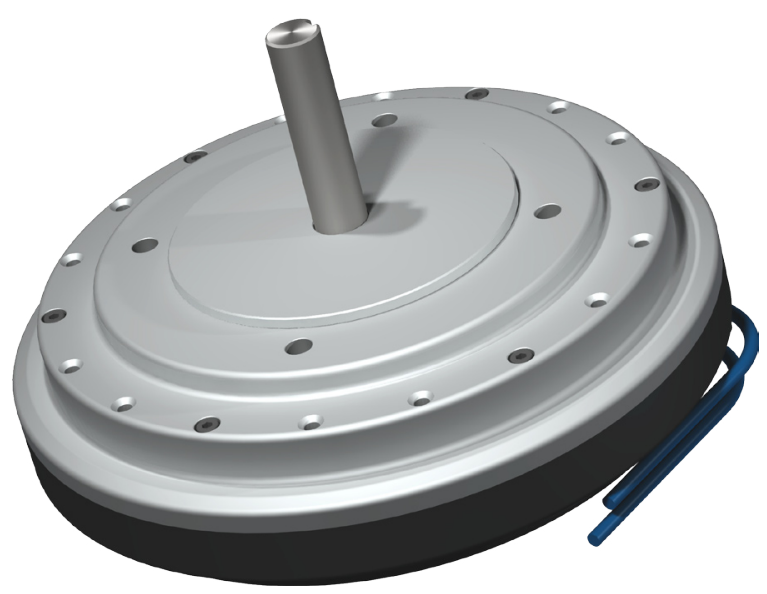

Steve Kraihanzel

Lenny Schrank

Jason M. Wolf

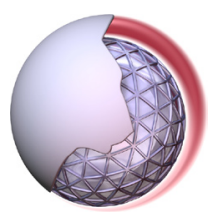

Kinetic Art \& Technology

9540 Highway 150

PO Box 250

Greenville, Indiana 47124-0250

(812) 923-7474 



\section{EXECUTIVE SUMmARY \& OVERVIEW \\ (1)}

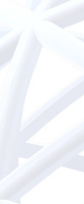

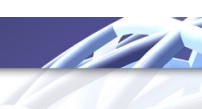

\section{YAV}

$\mathrm{F}_{\mathrm{t}=\mathrm{s}}^{\mathrm{s}}$ or a product development effort to be successful, it must combine innovation, technical feasibility, and commercial viability. Many well intentioned R\&D development projects have succeeded with the first two requirements, while failing at the third. This trend has been pointed out by various Government agencies, such as the General Accounting Office. Unfortunately, automotive research has had its share of programs that were technical successes, but commercial failures. Sometimes this may occur because the innovation, while being technically viable, is not solving a problem that is of immediate concern for the automotive industry. In other cases, the incremental gain in performance produced by the innovation is viewed by the auto companies as too small to justify the cost of changing production infrastructure. Because of this installed infrastructure and the cost-sensitive nature of the products, the US automotive industry is considered by many to be among the most difficult industries in which to introduce new technology. Recognizing this, the Federal Government has funded several programs to facilitate the development and demonstration of new technologies that could bring advantage to US auto companies, should they be implemented in future vehicles. The Department of Energy's (DOE) CARAT program has been one of these.

For many reasons, including fulfilling its mission and to insure future funding, the DOE needs a steady stream of R\&D “success stories." Kinetic Art \& Technology Corporation (KAT) and it's sister company, Lynx Motion Technology Corporation (Lynx) also have the need to become DOE success stories for the sake of their employees, stockholders, and customers. This CARAT effort has helped KAT/ Lynx to give evidence of the scientific validity of its innovative motor technology, while showing a path to market that will greatly improve the chances that companies will actually buy large numbers of the resulting products. As a result of this CARAT program, along with a parallel Lynx/KAT commercialization effort, highvolume production of motor and controller products can begin relatively quickly, producing numerous jobs, while significantly lowering the cost of these products to the automotive industry and other markets.

Throughout this CARAT effort, the technical objectives have been refined and refocused. Some objectives have been greatly expanded, while others have been minimized. The determining factor in all decisions to refocus the objectives was the commercial need, primarily the needs of Lynx/KAT manufacturing partners.
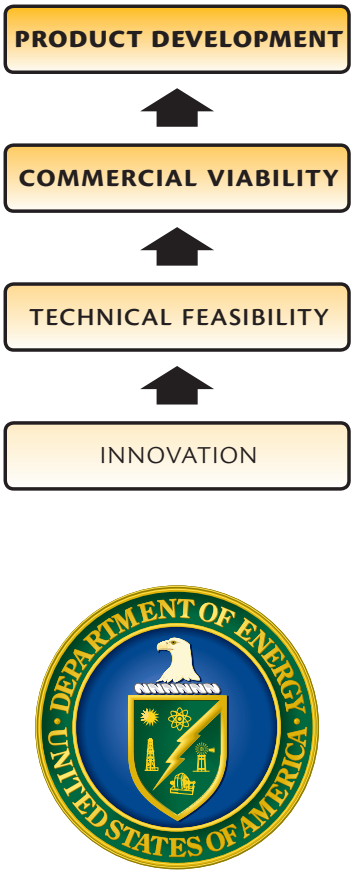


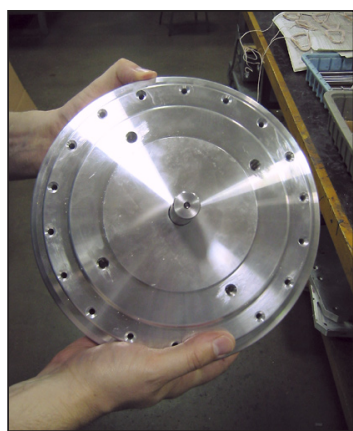

There is significant commercial need for the new E225 SEMA motor. This proposal uses the E225 as the baseline for performance and reduction in cost.

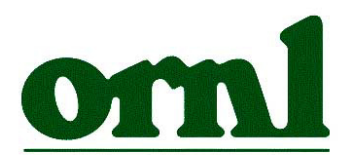

OAK RIDGE NATIONAL LABORATORY
Since the time of the initial CARAT proposal submittal, several companies have expressed interest in employing the resulting motor and controller in commercial products. Two of these companies have committed to providing cost share in order to facilitate the development. One of these companies is a first-tier automotive supplier developing a revolutionary new family of products requiring the ultra-high system efficiency achievable by the Lynx/KAT motor and controller technologies (known as Segmented ElectroMagnetic Array, or SEMA technology). Another company requires the high efficiency, quiet operation, and control characteristics afforded by the same basic motor and controller for an advanced air filtration product. The combined annual production requirement projected by these two companies exceeds one million units by 2005. In addition, several other lowervolume users are expected to begin ordering motors in the near future. Other potential high-volume users have also been identified. The performance specifications for this highly-marketable SEMA motor, designated the E225, are given in Appendix A.

The combination of these needs for very similar motors and controls, along with the maturity of the Lynx/KAT technology offers a rare opportunity for rapid commercialization. As the DOE has been a significant sponsor of this technology, the Department of Energy should receive significant positive publicity for its instrumental role in bringing this highly-efficient motor technology from the laboratory into the marketplace. KAT could benefit from assistance from Oak Ridge National Laboratories (ORNL) in the area of power electronics design, and had proposed that a portion of funding from a related SBIR be used to support that work. This kind of collaboration would have strengthened the ties between a major Federal Laboratory and a commercial consortium. Such collaboration would have brought additional future benefit to the companies involved and to ORNL, being another example of how industry involvement with the Federal Labs brings about commercial success. Unfortunately, the related DOE SBIR was not funded. The lack of this SBIR funding has significantly slowed the pace of SEMA development as this CARAT effort has come to a close. KAT/Lynx commercial partners were depending on DOE R\&D funding to leverage their investment and help ease the path toward commercialization. KAT/Lynx will look for other opportunities for collaboration with the Department of Energy.

Significant private investment has been and will continue to be invested in order to commercialize the Lynx/KAT motor technology. The majority of future private investment will be spent in setting up the facilities needed for high-volume production of motors and controls. There remain technical issues, however, that need to be addressed to prepare the technology for cost-sensitive products, such as those needed by the automotive industry. KAT/Lynx will continue to look for $\mathrm{R} \& \mathrm{D}$ funding (both commercial and government) to perform these technical tasks. Once these tasks are done, they will feed into privately-funded production efforts. This has been the model followed throughout this CARAT effort, which has had a high degree of "cost share" associated with it. This has shown the com- 
mitment of the several commercial entities at work on this project and will further increase the likelihood of creating a success story for DOE and all involved.

KAT and its commercialization Partner, Lynx, have now demonstrated motors based on SEMA technology in many prototypes, commercial products, and military applications. Over the past seven years, SEMA motors and generators have been built in sizes ranging from three inches in diameter (fractional horsepower) up to thirty-three inches (hundreds of horsepower). Running with standard commercial motor controllers, these SEMA systems have proven to be efficient, lightweight, precise, and easy to control. With assistance from Oak Ridge National Laboratory and the University of Louisville, KAT has developed several generations of electronics and algorithms to take special advantage of the SEMA's unique control characteristics and to further improve efficiency, peak torque, accuracy, and bandwidth.

With the SEMA motor's proven technical performance, dozens of prototypes tested, and commercial products in the field, Lynx/KAT is now developing the E225 motor and associated controller for new products from a major automotive supplier and has gained significant interest from several other potential users of SEMA-based products. The E225 initial prototype was first built under this CARAT effort. The first-tier automotive supplier and other OEMs are incorporating SEMA motors into their new products. This should lead to high-volume manufacturing of motors and control electronics in the relatively near future.

Lynx/KAT has assembled a group of manufacturers and material suppliers that are eager to ramp up production to meet the needs of the automotive supplier and others. One of these, Global Trading Company, is committing resources to establish manufacturing infrastructure. Bodine Electric Company, which has been manufacturing SEMA motors for over three years, is another Lynx/KAT partner that is expanding production capacity. Investors have also been identified to supply funding to expand production facilities to meet the anticipated demand for SEMA motor systems.

And so, most of the ingredients for a successful high-tech manufacturing business consortium are being assembled: customers who want to buy SEMA motors; manufactures and suppliers who want to build and sell those motors; and investors who want to supply the funding to start the process.

One critical ingredient is still missing, however: a pre-production prototype that can be shown to be producible in large volume and at low cost. This is why additional R\&D beyond this CARAT effort is so important. The KAT/Lynx Team have now established a plan for adding to the existing SEMA technology to allow high-volume production and significantly reduce the production cost while preserving the performance benefits needed by OEMs.

By providing the missing prototypes and processes, additional R\&D efforts will become the catalyst to cause each player in this SEMA motor consortium to invest their part. Without the resulting proof-of-mass-production technology, the investors are reluctant to invest. Without investment, the manufacturers cannot expand 


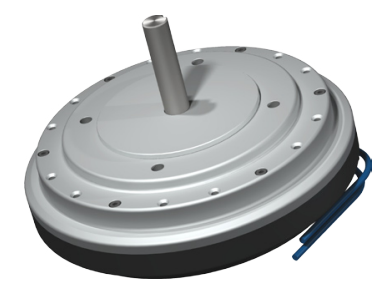

By providing an initial prototype, this CARAT effort has laid a foundation for the SEMA motor consortium. production capacity fast enough to convince customers to order large numbers of motor systems. With additional development effort, however, all the members in this consortium will simultaneously see that the fundamental barriers to high-volume production have been overcome. The customers, manufacturers, and investors will all see together how the deal can be done. Because these members have made funding commitments to leverage $R \& D$ funding (whether government or commercial), each will have an added incentive to see their investment pay off in the production stage. Because of the large number of motors needed (projections of over one million by the end of 2005), this scenario will create a significant number of jobs in several sectors.

As with any technical and business venture, there are risks of failure in this commercialization effort. The KAT/Lynx team has worked to reduce the risk, but the team has focused even more on maximizing the potential. With very stable and innovative partners like the first-tier automotive supplier and Bodine Electric Company (in business since 1905), and with new partners like Global Trading Company, the KAT/Lynx team knows that, with perseverance, technical and commercial success will follow. 


\section{Technical Progress}

\section{Motor Design}

\section{Electromagnetic Design}

The specifications for the motor designed under this program were based on the requirements from a tier-one automotive supplier. Future variations of the motor are also likely to become Bodine products, under license to Lynx.

The electromagnetic design of this motor was optimized for efficiency. The rated point (in this case, 3,000 rpm and 1,100 W) falls at a point where the most efficient design is significantly influenced by all loss factors in the motor (e.g. $\mathrm{I}^{2} \mathrm{R}$, bearing

\begin{tabular}{|c|c|c|}
\hline Design Parameters & $3,000 \mathrm{rpm}$ & 6,000 rpm \\
\hline Rated Continuous Power & $1,100 \mathrm{~W}$ & $1,800 \mathrm{~W}$ \\
\hline Poles & 12 & 12 \\
\hline Motor Outside Diameter & $225 \mathrm{~mm}$ & $225 \mathrm{~mm}$ \\
\hline Approximate System Efficiency & $91.5 \%$ & $91.8 \%$ \\
\hline Motor Efficiency & $96.1 \%$ & $95.1 \%$ \\
\hline Outer Magnetic Diameter & $170 \mathrm{~mm}$ & $170 \mathrm{~mm}$ \\
\hline Approximate Motor Length & $50 \mathrm{~mm}$ & $50 \mathrm{~mm}$ \\
\hline Phase Current & $6.49 \mathrm{~A}_{\mathrm{rms}}$ & $5.44 \mathrm{~A}_{\mathrm{rms}}$ \\
\hline Phase Resistance & $180.95 \Omega$ & $180.94 \Omega$ \\
\hline Phase Inductance & $73.63 \mu \mathrm{H}$ & $73.63 \mu \mathrm{H}$ \\
\hline Phase Voltage & $59.31 \mathrm{~V}_{\mathrm{rms}}$ & $117.25 \mathrm{~V}_{\mathrm{rms}}$ \\
\hline Line-to-Line Voltage & $204.91 \mathrm{~V}$ & $204.91 \mathrm{~V}$ \\
\hline Bus Voltage & $131.44 V_{D C}$ & $131.44 V_{D C}$ \\
\hline Bus Current & $9.06 A_{D C}$ & $15.01 A_{D C}$ \\
\hline Torque Constant & $0.398 \mathrm{lbf} \cdot f t / A_{r m s}$ & $0.388 \mathrm{lbf} \cdot \mathrm{ft} / \mathrm{A}_{\mathrm{rms}}$ \\
\hline Approximate Active weight & $3.27 \mathrm{~kg}$ & $3.27 \mathrm{~kg}$ \\
\hline Approximate Total Weight & $4.66 \mathrm{~kg}$ & $4.66 \mathrm{~kg}$ \\
\hline Approximate Copper Weight & $0.72 \mathrm{~kg}$ & $0.72 \mathrm{~kg}$ \\
\hline Magnet Weight & $1.20 \mathrm{~kg}$ & $1.20 \mathrm{~kg}$ \\
\hline
\end{tabular}


loss, aerodynamic drag, and eddy-current loss). Since none of the major loss factors were negligible, the optimization process was somewhat involved. The table shows some of the major parameters of the design. Both columns are the same design, shown at different operating points. The first is 3,000 rpm and 1,100 W; the second is $6,000 \mathrm{rpm}$ and $1,800 \mathrm{~W}$.

\section{Mechanical Design}

The mechanical design was carried out simultaneously with the electromagnetic design. The design was based on a parametric solid model that could be scaled easily to suit the optimized electromagnetic design.

\section{Conforming to Standard Motor Mechanical Interfaces}

As part of the mechanical design, an attempt was made to conform to the Metric IEC and ICS motor standards for mechanical interface. Thorough research of the applicable standards was conducted with the results implemented in the design. The four mechanical interfaces considered included:

- B3 Foot Mount

- B5 Flange Mount

- $\mathrm{B}_{3} / \mathrm{B}_{5}$ Foot/Flange Mount (combination mount)

- B14 Face Mount

The profile of an axial gap motor typically differs from that of a conventional motor since an axial-gap motor has a "diameter to axial length ratio" that is greater than 1:1 and is typically greater than 3:1. Because of this unique profile, the horsepower per typical mounting size will differ with all interface types. However, the motor was designed to comply with a standard even if the typical horsepower of the standard chosen was for a larger horsepower than that of the prototype motor. It is noteworthy to mention that increased horsepower per diameter is possible with the Lynx axial gap motor by adding more "slices" to the motor (called a multislice motor), which in turn increases the axial length of the motor.

In the case of the Foot Mount and B14 Face Mount, there are two motor frame sizes having compatible motor interfaces with the prototype motor. These sizes are IEC Metric sizes DF1oo and DF112. A comparison of motor dimensions, horsepower, and torque are presented in the following table. These dimensions have a direct affect on the $\mathrm{B}_{3}$ Foot Mount and $\mathrm{B}_{14}$ Face Mount but do not necessarily have a direct affect on the $\mathrm{B}_{5}$ Flange Mount.

Due to the unique profile of the axial gap motor, the B3 Foot Mount is not completely compatible with either the DF10o or DF112 Foot Mount. The lateral-hole separation (IEC $\operatorname{dim} \mathrm{A}$ ) is the same as the DF112, but the axial distance from the face to first set of holes is $30 \mathrm{~mm}$, versus $70 \mathrm{~mm}$ for the DF112. In addition, there is not a second set of holes in the prototype motor per the DF112 foot mount stan- 


\begin{tabular}{|lccc|}
\hline Frame Size & DF100 & DF112 & Prototype \\
Housing Outside Diameter $(\mathrm{mm})$ & 215 & 220 & 225 \\
\hline Length Range $(\mathrm{mm})$ & $306-410$ & $306-410$ & 75.0 \\
Shaft Diameter $(\mathrm{mm})$ & 28 & 28 & 16 \\
Power Range $(\mathrm{hp})$ & $2-4$ & $3-5.5$ & 1.0 \\
Maximum Torque $(\mathrm{N} \cdot \mathrm{m})^{1}$ & 31.5 & 31.5 & $4.1^{2}$ \\
\hline
\end{tabular}

${ }^{1}$ Based on shaft diameter from ICS 16-2001 standard.

${ }^{2}$ To help meet efficiency goals, the bearing size was minimized, which drove the shaft diameter. $\mathrm{A}$ larger shaft could be used but efficiency would suffer. A larger shaft could also be used for a multislice motor.

dard. Note that the shaft length is longer than the standard due to application specific criteria.

The B14 Face Mount used is also typical for a DF10o- or DF112-size IEC motor frame. This size could be changed to meet a motor with closer performance values if desired, but the diameter of the axial-gap motor will be larger than its conventional counterpart.

Concerning the flange size, an FF215 Flange Mount per ICS 16-2001 was chosen for this prototype. This is a typical flange size for a DF10o or DF112 IEC frame. It was designed to fit onto the B14 Face Mount described earlier.

The final mechanical interface considered was the foot-mount/flange-mount combination. It is simply a combination of the DF112 Foot Mount and FF215 Flange Mount discussed above.

\section{Rotor Design}

The source of energy used to move the air through the motor is the spinning rotor assembly. Shear forces as well as pumping action due to vanes created by spacing between the magnets cause the air to move from the inner sections of the rotor to the outer diameter of the rotor. These forces are a source of power loss. However, if no air is allowed to move through the motor, excessive losses occur due to the heating of the active components. A key to optimizing the losses due to aerodynamic drag and the heating of motor active components is to find the magnet gap profile that will provide the optimal point wherein the sum of the power loss due to aerodynamic drag and the power loss due to heating of the active components is minimized. With too much airflow, the drag will be high with very little improvement in active component temperatures. With too little airflow, the performance will suffer due to heating. Determining the magnet gap profile that will result in minimum loss is a key to designing the most efficient motor.

To find the optimal geometry it was planned that a series of fillers, varying in axial height, be added between the magnets of the rotor assembly. Four sets of fillers were to be made from a lightweight plastic with axial height equal to $25 \%, 50 \%$, and $75 \%$ of the magnet axial height, as well as a set equal to the magnet height and 


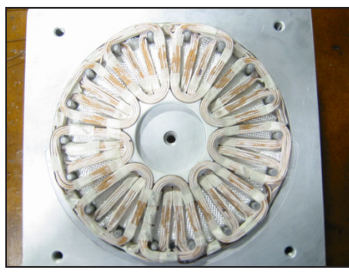

Wound SEMA Litz-wire coils in platter mold

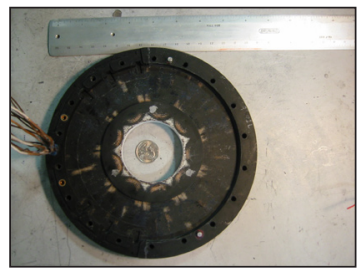

Completed potted stator assembly

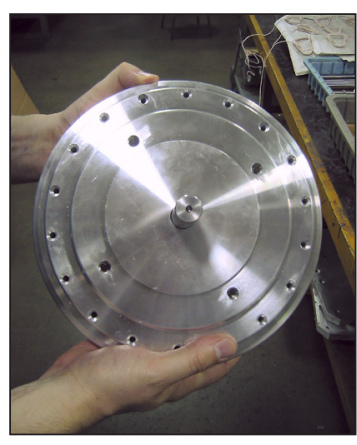

filling in the whole gap. However, testing that was first performed of the rotor assembly with no filler between the magnets showed that aerodynamic drag was not significant enough to be a concern.

\section{Rotor Structural Analysis}

Minimizing the outer lip of the flux return provides room for more magnet material at the OD for a given motor diameter, providing more flux at the best flux linkage point. The more magnet material at the $\mathrm{OD}$, the less total magnet material required, minimizing magnet weight and cost. Finite Element Analysis (FEA) was performed on the rotor lip in order to find the minimum lip thickness. Assumptions included:

- 1020 steel, Normalized at $870^{\circ} \mathrm{C}\left(1,600^{\circ} \mathrm{F}\right)$

- Glue failure

- Centrifugal force from magnet calculated and applied

- Axial force due to magnetic force applied

- Spinning at maximum speed $=5,000 \mathrm{rpm}$

- Maximum allowable stress $=$ Yield $/ 2=25,000$ psi

The minimum lip thickness was found to be $1.5 \mathrm{~mm}$.

\section{Detail Design}

During the detail design of the prototype motor, additional considerations were integrated into the design. Items included:

- Standard mechanical interfaces

- Through-shaft cooling

- Rotor design (for efficiency and structural integrity)

- Mold design flexibility

The foot-mount mechanical interface was used, and the shaft was made longer than a standard motor to accommodate the application in which the motor was tested.

\section{Motor Assembly}

During the initial phases of the design, KAT completed all the motor and tooling fabrication drawings. Bodine Electric, with support from KAT's engineers, completed fabrication of the tooling and the individual motor components. KAT engineers assisted in Bodine's successful completion of their first Litz-wire coil build. These Litz-wire coils were assembled into the stator mold along with thermocouples and Hall-effect sensors and then epoxy injected. The resulting coil platter was assembled into the complete motor, which KAT has designated the E225. 


\section{Controller Design}

A DSP-based, low-voltage motor controller previously developed by KAT provided the basis for the new high-voltage controller developed in this CARAT program. The controller uses a separate MOSFET H-bridge to drive each phase of the motor. Linear or digital Hall-effect sensors are used for position sensing. These are small and inexpensive compared to conventional encoders and resolvers. SEMA ironless motors tend to have very low inductance. By utilizing a separate $\mathrm{H}$-bridge control approach, the SEMA motor stator design benefits by an increased number of turns per coil, which increases the inductance. The use of discrete MOSFETS also reduces the cost and the size of the controller and allows higher PWM frequency switching.

KAT completed the design of the high voltage controller and built the first prototype using a DSP evaluation board from Spectrum Digital, Inc. and an application-specific control board and power board.

The controller consists of three MOSFET H-bridges to drive three phases of the motor. The digital Hall-effect sensors, which are embedded inside the motor, provide the position information, and the phase currents are sensed using resistive current sensors. These sensor signals are made compatible and fed to the DSP. Based on this information, the DSP provides digital control signals to the MOSFET gate drivers for correct switching of the MOSFETs. The controller can be programmed to achieve either speed or torque control.

\section{Proof of Concept Controller}

For ease of prototyping, KAT elected to use an off-the-shelf TMS320LF2407 DSP evaluation board from Spectrum Digital, Inc. in combination with a control board and power board designed in-house to interface the evaluation board with the motor. The evaluation board hosts a TMS320LF2407 DSP from Texas Instruments, which provides low-cost, low-power, and high-performance processing capabilities optimized for digital motor and motion control applications. Capabilities of the DSP include centered- and/or edge-aligned PWM generation, synchronized analog-to-digital conversion, a 10-bit analog-to-digital converter (ADC) with a minimum conversion time of $500 \mathrm{~ns}$, and up to 16 channels of analog input.

The control board comprises three amplifiers for amplifying the voltages proportional to the current in each phase of the motor from three current sensors. This information is used to close the current control loop and check limiting current conditions. There are three comparators for level shifting and amplifying the voltage outputs from three Hall-effect sensors placed 120 electrical degrees apart in the stator windings. This is the rotor position information used to close control loops for current and velocity. It also has the gate drivers for the MOSFETs and fault sensing and shutdown circuitry for protection.

Three independent H-bridges comprising of four MOSFETs each drive three phases of the motor separately. This topology helps to simplify the motor design. It allows lower current per phase and a greater number of turns to enhance the in-

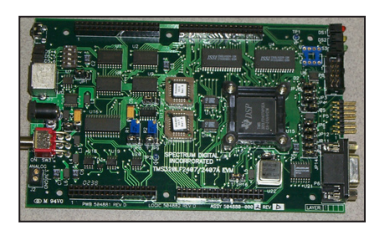

DSP evaluation board

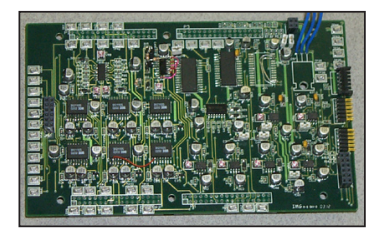

Control board

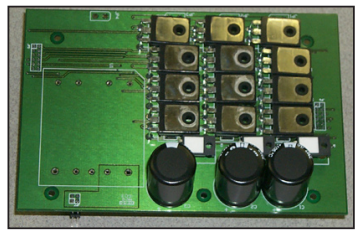

Power board (without heatsink) 


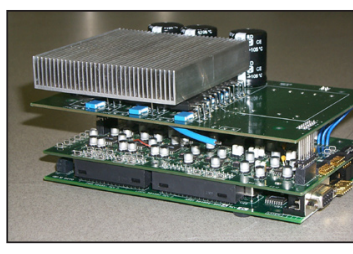

Board assembly

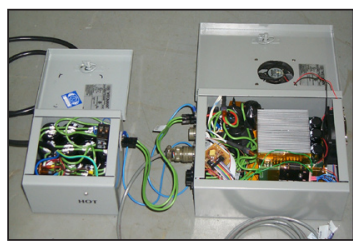

Controller and rectifier in enclosures

ductance by allowing increased voltage per phase of the windings without sacrificing the motor performance. One current-sense resistor on each $\mathrm{H}$-bridge reads the current from each phase of the motor. The use of discrete MOSFETs also reduces the cost and the size of the controller and allows higher-frequency PWM switching.

\section{Controller Assembly}

The DSP board, control board, and power board were assembled into enclosures. Once fully assembled, the controller was connected to a bench-top DC power supply and tested with and without the load motor. Testing with the low inductance CARAT motor resulted in additional inductance being added at the output of the controller.

In addition to the controller itself, a passive rectifier was assembled and tested. This rectifier was designed to operate from 120 VAC input. The rectifier was connected to the controller and integration testing continued with the motor. As mentioned earlier, the end customer's primary design parameter was keeping the system (motor, controller, and rectifier) efficiency above 90\% at all operating points. The test data provided indicates the system's ability to reach that goal.

\section{Test Results}

The following data was collected at Bodine's facility and in-house at the KAT test labs. Note that efficiency measurements near 100\% efficiency (around 90\% and above) are very sensitive to noise and slight miscalibrations. As a result, some efficiencies are falsely indicated as being higher than $100 \%$.

\section{Motor Lead Parameters}

\begin{tabular}{|ccc|}
\hline Motor Phase & Resistance & Inductance \\
A & $175.8 \mathrm{~m} \Omega$ & $63.2 \mu \mathrm{H}$ \\
\hline B & $158.4 \mathrm{~m} \Omega$ & $62.7 \mu \mathrm{H}$ \\
C & $162.0 \mathrm{~m} \Omega$ & $62.7 \mu \mathrm{H}$ \\
\hline
\end{tabular}

\section{Motor Back-EMF}

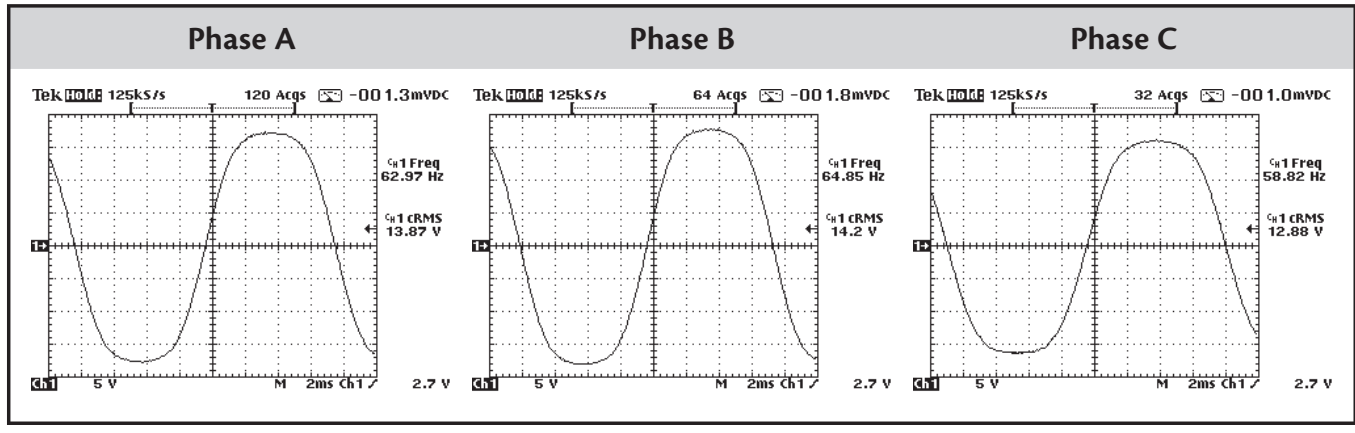




\section{Motor Performance Data Provided by Bodine}

As described earlier, the E225 is designed to operate utilizing the KAT H-bridge drive technology. The customer's application that was targeted for the design was based on a rectified $110 \mathrm{~V}_{\mathrm{AC}}$ input. Because Bodine did not have an $\mathrm{H}$-Bridge controller available to drive the motor, the motor phases were connected into a wye connection for use with a standard commercial drive. To operate the motor at its designed speed and torque operating points in this wye configuration, it was necessary that Bodine operate the motor with a drive providing twice the DC bus

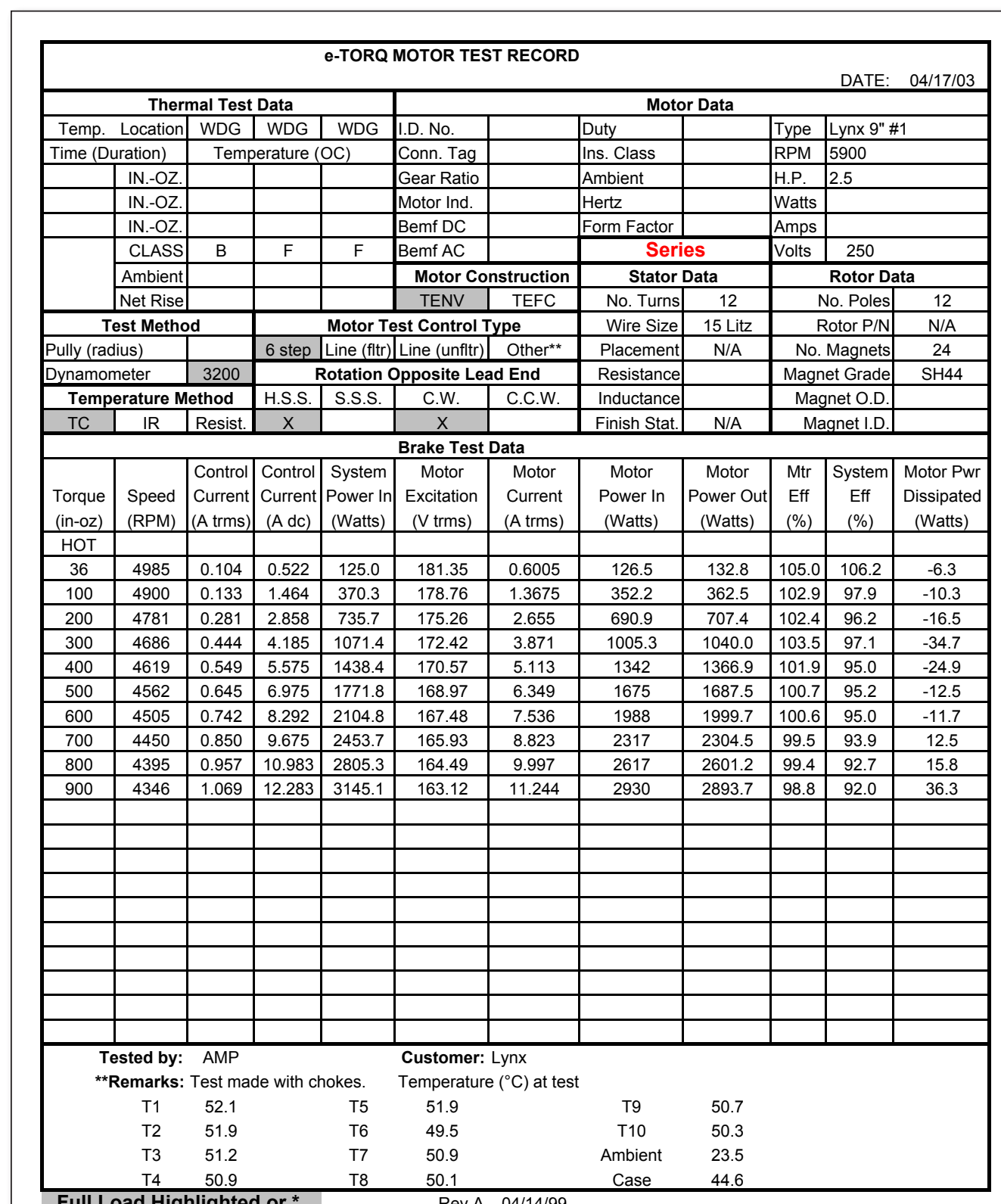

Note: efficiencies are calculated and those indicated over $100 \%$ may be due to calibration errors or sensitivity to noise 
source that will be used in the field. This is due to the bus now being dropped across two phases instead of the single phase when the motor is configured to operate from the H-Bridge controller. The two bus voltages used for the Bodine testing were selected to simulate the voltage range at which the motor has to operate in the field.

\begin{tabular}{|c|c|c|c|c|c|c|c|c|c|c|c|}
\hline \multirow{2}{*}{\multicolumn{10}{|c|}{ e-TORQ MOTOR TEST RECORD }} & \multirow[b]{2}{*}{ DATE: } & \multirow[b]{2}{*}{$04 / 17 / 03$} \\
\hline & & & & & & & & & & & \\
\hline \multicolumn{5}{|c|}{ Thermal Test Data } & \multicolumn{7}{|c|}{ Motor Data } \\
\hline Temp. & Location & WDG & WDG & WDG & I.D. No. & & Duty & & Type & \multicolumn{2}{|c|}{ Lynx 9" \#1 } \\
\hline \multicolumn{2}{|c|}{ Time (Duration) } & \multicolumn{3}{|c|}{ Temperature $(\mathrm{OC})$} & Conn. Tag & & Ins. Class & & RPM & \multicolumn{2}{|l|}{5900} \\
\hline & IN.-OZ. & & & & Gear Ratio & & Ambient & & H.P. & \multicolumn{2}{|l|}{2.5} \\
\hline & IN.-OZ. & & & & Motor Ind. & & Hertz & & Watts & \\
\hline & IN.-OZ. & & & & Bemf DC & & Form Factor & & Amps & \multicolumn{2}{|l|}{\begin{tabular}{|l|l|} 
\\
\end{tabular}} \\
\hline & CLASS & $\mathrm{B}$ & $\mathrm{F}$ & $\mathrm{F}$ & Bemf AC & & \multicolumn{2}{|c|}{ Series } & Volts & \multicolumn{2}{|l|}{$310 \mathrm{~V}$} \\
\hline & Ambient & & & & \multicolumn{2}{|c|}{ Motor Construction } & \multicolumn{2}{|c|}{ Stator Data } & \multicolumn{3}{|c|}{ Rotor Data } \\
\hline & Net Rise & & & & TENV & TEFC & No. Turns & 12 & \multicolumn{2}{|r|}{ No. Poles } & 12 \\
\hline \multicolumn{3}{|c|}{ Test Method } & \multicolumn{4}{|c|}{ Motor Test Control Type } & Wire Size & 15 Litz & \multicolumn{2}{|c|}{ Rotor $\mathrm{P} / \mathrm{N}$} & $\mathrm{N} / \mathrm{A}$ \\
\hline Pully (rac & dius) & & 6 step & Line (fltr) & Line (unfltr) & Other** & Placement & $\mathrm{N} / \mathrm{A}$ & No. & Magnets & 24 \\
\hline Dynamor & meter & 3200 & & Rotation O & Opposite Lea & d End & Resistance & & Magn & et Grade & $\mathrm{SH} 44$ \\
\hline Temp & erature $\mathrm{M}$ & lethod & H.S.S. & S.S.S. & C.W. & C.C.W. & Inductance & & Mag & gnet O.D. & \\
\hline $\mathrm{TC}$ & IR & Resist. & $x$ & & $x$ & & Finish Stat. & $\mathrm{N} / \mathrm{A}$ & $\mathrm{Ma}$ & ganet I.D. & \\
\hline & & & & & Brake Test & Data & & & & & \\
\hline $\begin{array}{l}\text { Torque } \\
\text { (in-oz) }\end{array}$ & $\begin{array}{l}\text { Speed } \\
\text { (RPM) }\end{array}$ & \begin{tabular}{|c|} 
Control \\
Current \\
(A trms) \\
\end{tabular} & $\begin{array}{c}\text { Control } \\
\text { Current } \\
(\mathrm{A} \text { dc }) \\
\end{array}$ & $\begin{array}{c}\text { System } \\
\text { Power In } \\
\text { (Watts) }\end{array}$ & \begin{tabular}{|c|} 
Motor \\
Excitation \\
$(\mathrm{V}$ trms $)$ \\
\end{tabular} & $\begin{array}{c}\text { Motor } \\
\text { Current } \\
\text { (A trms) }\end{array}$ & $\begin{array}{c}\text { Motor } \\
\text { Power In } \\
\text { (Watts) }\end{array}$ & \begin{tabular}{|c|}
$\begin{array}{c}\text { Motor } \\
\text { Power Out } \\
\text { (Watts) }\end{array}$ \\
\end{tabular} & $\begin{array}{l}\text { Mtr } \\
\text { Eff } \\
(\%) \\
\end{array}$ & $\begin{array}{c}\text { System } \\
\text { Eff } \\
(\%)\end{array}$ & $\begin{array}{c}\text { Motor Pwr } \\
\text { Dissipated } \\
\text { (Watts) }\end{array}$ \\
\hline HOT & & & & & & & & & & & \\
\hline 78 & 6069 & 0.142 & 1.315 & 399.4 & 221.99 & 1.2730 & 398.0 & 350.2 & 88.0 & 87.7 & 47.8 \\
\hline 100 & 6056 & 0.154 & 1.442 & 438.1 & 221.55 & 1.3860 & 433.0 & 448.0 & 103.5 & 102.3 & -15.0 \\
\hline 200 & 5919 & 0.319 & 2.782 & 858.8 & 217.42 & 2.611 & 832.0 & 875.8 & 105.3 & 102.0 & -43.8 \\
\hline 300 & 5796 & 0.502 & 4.089 & 1270.4 & 213.61 & 3.847 & 1218.0 & 1286.4 & 105.6 & 101.3 & -68.4 \\
\hline 400 & 5695 & 0.668 & 5.388 & 1690.0 & 210.58 & 5.063 & 1603 & 1685.3 & 105.1 & 99.7 & -82.3 \\
\hline 500 & 5628 & 0.784 & 6.698 & 2103.5 & 208.59 & 6.237 & 1991 & 2081.8 & 104.6 & 99.0 & -90.8 \\
\hline 600 & 5566 & 0.888 & 7.797 & 2523.4 & 206.81 & 7.410 & 2377 & 2470.7 & 103.9 & 97.9 & -93.7 \\
\hline 700 & 5506 & 0.996 & 9.293 & 2922.7 & 205.08 & 8.600 & 2759 & 2851.4 & 103.3 & 97.6 & -92.4 \\
\hline 800 & 5447 & 1.106 & 10.582 & 3331.5 & 203.40 & 8.803 & 3137 & 3223.8 & \begin{tabular}{|l|}
102.8 \\
\end{tabular} & 96.8 & -86.8 \\
\hline 900 & 5392 & 1.208 & 11.777 & 3710.4 & 201.81 & 10.908 & 3482 & 3590.1 & \begin{tabular}{|l|}
103.1 \\
\end{tabular} & 96.8 & -108.1 \\
\hline & & & & & & & & & & & \\
\hline & & & & & & & & & & & \\
\hline & & & & & & & & & & & \\
\hline & & & & & & & & & & & \\
\hline & & & & & & & & & & & \\
\hline & & & & & & & & & & & \\
\hline & & & & & & & & & & & \\
\hline & & & & & & & & & & & \\
\hline & & & & & & & & & & & \\
\hline & ested by: & AMP & & & Customer: & $-y n x$ & & & & & \\
\hline & Remarks: & Test mac & de with ch & hokes. & Temperature & $\left({ }^{\circ} \mathrm{C}\right)$ at test & & & & & \\
\hline & $\mathrm{T} 1$ & 51.9 & & T5 & 50.4 & & T9 & 50.5 & & & \\
\hline & T2 & 51.2 & & T6 & 49.4 & & $\mathrm{~T} 10$ & 50.0 & & & \\
\hline & T3 & 50.9 & & $\mathrm{~T} 7$ & 50.4 & & Ambient & 24.0 & & & \\
\hline & T4 & 50.7 & & T8 & 50.1 & & Case & 45.0 & & & \\
\hline
\end{tabular}

Full Load Highlighted or *

Rev A 04/14/99

Note: efficiencies are calculated and those indicated over $100 \%$ may be due to calibration errors or sensitivity to noise 


\section{Motor Performance Data from KAT Test Facility}

The data provided below was obtained at the KAT test facility. The motor was installed in an eddy-current dynamometer buit by KAT. Test data was collected using a National Semiconductor data aquisition system. The motor was powered by the $\mathrm{H}$-bridge controller developed and built during this program.

\begin{tabular}{|ccccccccc|}
\hline $\begin{array}{c}\text { Motor } \\
\text { Speed } \\
(\mathrm{rpm})\end{array}$ & $\begin{array}{c}\text { Motor } \\
\text { Torque } \\
(\text { Ibf-in) }\end{array}$ & $\begin{array}{c}\text { Average } \\
\text { Bus } \\
\text { Voltage } \\
\left(\mathrm{V}_{\mathrm{DC}}\right)\end{array}$ & $\begin{array}{c}\text { RMS } \\
\text { Bus } \\
\text { Current } \\
\left(\mathrm{A}_{\mathrm{rms}}\right)\end{array}$ & $\begin{array}{c}\text { Input } \\
\text { power } \\
(\mathrm{W})\end{array}$ & $\begin{array}{c}\text { Heatsink } \\
\text { Temp } \\
\left({ }^{\circ} \mathrm{C}\right)\end{array}$ & $\begin{array}{c}\text { Motor } \\
\text { Temp } \\
\left({ }^{\circ} \mathrm{C}\right)\end{array}$ & $\begin{array}{c}\text { System } \\
\text { Efficiency } \\
(\%)\end{array}$ & $\begin{array}{c}\text { Exductance } \\
\text { Ind Phase } \\
(\mu \mathrm{H})\end{array}$ \\
\hline 2960 & 31 & 142.7 & 8.9 & 1220 & 57 & 30 & 87.8 & \\
\hline 2950 & 29.8 & 142.6 & 8.8 & 1210 & 56 & 32 & 88.8 & \\
\hline 3950 & 25 & 142.6 & 9.9 & 1360 & 50 & 32 & 85.9 & 250 \\
\hline 3950 & 26.1 & 142.6 & 9.8 & 1350 & 50 & 28 & 90.4 & 250 \\
\hline 3940 & 28.1 & 143.2 & 10.4 & 1450 & 53 & 32 & 90.3 & 250 \\
\hline 5900 & 26.5 & 168.4 & 12.4 & 2000 & 39 & 33 & 92.5 & 250 \\
\hline 2960 & 30.05 & 143.6 & 8.3 & 1180 & 58.6 & 30.5 & 88.9 & 250 \\
\hline 3950 & 26.6 & 146.1 & 9.7 & 1370 & 52 & 32 & 90.07 & 250 \\
\hline 3950 & 26.2 & 146.1 & 9.7 & 1360 & 51 & 33.5 & 90 & 250 \\
\hline 4910 & 27.3 & 146 & 12.6 & 1750 & 53 & 36 & 90.06 & 250 \\
\hline
\end{tabular}

